\title{
Maternal and foetal outcome in patients referred to tertiary hospital
}

\author{
Nagar N. ${ }^{1}$, Gupta P. ${ }^{2}$ \\ ${ }^{1}$ Dr. Nidhi Nagar, Assistant Professor, Department of Obstetrics and Gynaecology, R.K.D.F. Medical College \& \\ Hospital, Bhopal, ${ }^{2}$ Dr. Prianka Gupta, Consultant/ Director Vedica Women and Fertility Clinic, Consultant Inamdar \\ Hospital, Pune, India
}

Corresponding Author: Dr. Nidhi Nagar, Assistant Professor, Department of Obstetrics and Gynaecology, R.K.D.F. Medical College \& Hospital, Bhopal (M.P.) India. E-mail: drnidhinagar24@gmail.com

\begin{abstract}
Objective: To know the incidence of referred patient to Sultaniazanana hospital. To evaluate maternal and foetal outcome in referred patients.To identify lacunae in appropriateness and timeliness of referral and to provide universal referral proforma for all patients referred from various health care facilities. Methods: The present study was done in Sultaniazanana hospital, Department of Obstetric\& Gynecology Gandhi Medical College, Bhopal, to study the referral from within Bhopal with respect to age, parity, place of referral, time of transport used, causes of referral, maternal \& perinatal outcome \& finally maternal deaths \& their causes. Results: Maximum patients are primigravida and of 20-30 years of age. Majority of patients used private vehicle \& only few have been provided with hospital ambulance. Most patients reached Sultaniazanana hospital within 2 hours, which is adequate for management of complications unless the patients is referred timely from the referring site. About $22.11 \%$ of patients are referred with no high risk factors \& $83.7 \%$ of patients are referred during emergency hours. Conclusion: Early identification, initiation of early treatment and timely referrals are the crucial components for success of any maternal health intervention.Minimizing the causes of delay to emergency obstetric care significantly decrease maternal and neonatal morbidity and mortality.
\end{abstract}

Keywords: Emergency, Referral, Maternal outcome, Neonatal mortality

\section{Introduction}

Madhya Pradesh is a state with high maternal mortality ratio which is now showing a declining trend because of various interventions that have been planned and implemented. However current trends are still far from achieving millennium development goals. Sultania Zanana hospital is Obstetric and Gynaecology department of Gandhi Medical College. Being a tertiary care center it caters lot of high risk obstetric patients. These referred patients are from various government and private hospital from within and outside Bhopal.

Obstetric complications claim 514,000 women's lives each year. Nearly all of these lives would be saved if good quality emergency obstetric care in made available 24 hours a day, 7 days a week. Most of these deaths are caused by haemorrhage obstructed labour, infection (sepsis), unsafe abortions and eclampsia. Indirect causes like malaria, HIV and anaemia also contribute to maternal deaths [1].

Manuscript received: $10^{\text {th }}$ February 2019

Reviewed: $20^{\text {th }}$ February 2019

Author Corrected: $25^{\text {th }}$ February 2019

Accepted for Publication: $28^{\text {th }}$ February 2019
About fifteen percent of all pregnancies will have some complication. Most complications occur randomly in both high and low risk patients. Life threatening complications can occur any time before, during and after delivery and quite often they are neither predictable nor preventable. However, if they are identified and addressed timely and if the basic and comprehensive emergency obstetric services are provided to all pregnant women closer to their homes; most of the maternal and perinatal deaths can be averted $[2,3]$.

Early identification, initiation of early treatment and timely referrals are the crucial components for success of any maternal health intervention. Therefore, it is imperative to impart the knowledge and skills for early identification of complications and initiation of early treatment to all the health functionaries of the state.

The delay occurs at the following three levels -

- Delay in decision to seek medical care.

- Delay in reaching health facility. 


\section{Original Research Article}

- Delay in receiving appropriate care at health facility due to staff insensitivity, lack of appropriate resources or poor organizational setups that is not conducive for emergency care.

The third delay (delay in receiving appropriate care at health facility) relates to factors in the health facility including quality of care. In practice it is crucial to address the third delay first, for it would be useless to facilitate access to a health facility, if it was not available, well-staffed, well equipped and providing good quality care[4].

Various health facilities within Bhopal are supposed to provide emergency obstetric carebut are not doing so, which causes overutilization of higher-level facilities like Sultaniazanana hospital. This is important because it has cost implications in resource constrained situations and because it may be detrimental to quality of care as the higher level facility becomes overburdened.

This study was conducted to evaluate obstetrics outcome in patients referred to Sultaniazanana hospital from within Bhopal. Various health facilities must provide the emergency obstetric care 24 hours a day, 7 days a week for successful implementation of safe motherhood programme.

\section{Materials and Methods}

The present study was a 1year prospective study conducted in Department of Obstetrics \& Gynaecology, Sultania Zanana Hospital \& Gandhi Medical College Bhopal, on 1249 obstetric patients in two phases. Each phase was of 6 month duration, In between two phases a workshop was conducted on strengthening of referral services to orient medical officers posted in various levels of health facilities regarding the referral system and protocol to be followed before referring the patient.

Selection of patients- All obstetric patients referred from inside Bhopal with or without referral letter.

\section{Exclusion criteria}

- All obstetric patients referred from outside Bhopal.

- Booked patient of Sultaniazanana hospital.

- All unbooked direct obstetrics patients to Sultaniazanana hospital.

A proforma was designed and data collected.The arrival time was recorded at Sultaniazanana hospital receiving room. The duration of stay at referring health institution was estimated by the patient in few and by their relatives in most cases.

Methods: All obstetric patients referred from inside Bhopal to Sultaniazanana hospital were studied. Detailed history was taken from patients or attendants regarding the age, Obstetric history, place of referral, duration of stay at referral centre, Management done at referral centre, Time and date of referral, Mode of conveyance and time taken Information given on referral letter.

Detailed clinical examination of the patient and findings noted in proforma.

The maternal outcome i.e. vaginal delivery, operative delivery and any other operative intervention and conservative management done was recorded.

Fetal outcome was recorded with reference to condition, need for NICU admission and still births and early neonatal deaths.

Statistical Analysis: The data of the present study was fed into the computer and after its proper validation, checking for error, coding and decoding were compiled and analysed with the help of SPSS 11.5 software for windows. Appropriate univariate and bivariate analysis and ANOVA (analysis of variance) for more than two means were carried out using t-test, calculated and tested. All means are expressed as mean + standard deviation. The critical values for the significance of the results were considered at 0.05 levels.

\section{Results}

A total 2717 obstetric patients were referred to Sultania Zanana Hospital contributing to $28.45 \%$ of total obstetric admissions, of which $45.96 \%$ were referred from within Bhopal.In between, a divisional level workshop, on Strengthening of referral services was held, which was a orientation program for all medical officers \& doctors in order to update their clinical knowledge \& skills.Maximum patients were primigravida and of 20-30 yrs of age. Jawaharlal Nehru Hospital, Berasia, private Hospital \& J.P. Hospital were the places from where maximum patients are referred. Majority of patients used private vehicle \& only few were provided with hospital ambulance. Most patients reached Sultania Zanana Hospital within 2 hours, which was adequate for management of complications unless the patients is referred timely from the referring site.About $22.11 \%$ of patients were referred with no high risk factors \& $83.7 \%$ of patients were referred during emergency hours. 
The present study is a prospective study of 1year period on 1249 obstetric patients conducted in two phases of 6 months each. In between the two phase, divisional level workshop on "Strengtheningof Referral Services" was conducted. Observations recorded in the study are as follows:

Table No.-1: Total number of patients.

\begin{tabular}{|l|l|c|}
\hline & No. & \% \\
\hline Total Number of Obstetric Admissions in SZH & 9551 & - \\
\hline Total Number of Referred Patients to SZH & 2717 & $54.03 \%$ \\
\hline Referred Patients from outside Bhopal & 1468 & $45.97 \%$ \\
\hline Referred Patients from Inside Bhopal & 1249 & \\
\hline
\end{tabular}

Total obstetric admissions during the study period were 9551 of which $28.45 \%$ were referred patients. Out of total referred patients $45.97 \%$ of patients are referred from inside Bhopal.

Table No.-2: Age wise distribution.

\begin{tabular}{|c|c|c|c|c|}
\hline \multirow{2}{*}{ Age } & \multicolumn{2}{|c|}{ Phase 1 } & Phase II \\
\cline { 2 - 5 } & No. & $\%$ & No. & $\%$ \\
\hline$<20 \mathrm{yrs}$ & 48 & 6.93 & 32 & 5.75 \\
\hline $20-30 \mathrm{yrs}$ & 561 & 81.06 & 479 & 85.91 \\
\hline $30-40 \mathrm{yrs}$ & 76 & 10.98 & 44 & 7.91 \\
\hline$>40$ yrs. & 07 & 1.03 & 02 & 0.43 \\
\hline Total & $\mathbf{6 9 2}$ & $\mathbf{1 0 0}$ & $\mathbf{5 5 7}$ & $\mathbf{1 0 0}$ \\
\hline
\end{tabular}

Maximum $83.2 \%$ of the patients were of age group 20-30 years. Because this age group has maximum fertility

Table No.-3: Parity wise distribution.

\begin{tabular}{|c|c|c|c|c|}
\hline \multirow{2}{*}{ Parity } & \multicolumn{2}{|c|}{ Phase 1 } & Phase II \\
\cline { 2 - 4 } & No. & $\%$ & No. & $\%$ \\
\hline Primi & 339 & 44.06 & 296 & 53.14 \\
\hline Multi & 309 & 44.65 & 249 & 44.70 \\
\hline Grandmulti & 44 & 6.29 & 12 & 2.16 \\
\hline Total & $\mathbf{6 9 2}$ & $\mathbf{1 0 0}$ & $\mathbf{5 5 7}$ & $\mathbf{1 0 0}$ \\
\hline
\end{tabular}

During the study period, maximum patients referred are primigravida (50.8\%). Maximum number of the patients are referred from Jawaharlal Nehru Hospital contributing to $16.97 \%$ of the total patients referred. This is followed by CHC Berasia (14.49\%), private hospital (13.3\%) and JP hospital (12.16\%). Maximum 83.7\% of the patients from within Bhopal were referred to SZH during 2pm-8am i.e. during emergency hours

Table No.-4: Type of transport.

\begin{tabular}{|c|c|c|c|c|}
\hline \multirow{2}{*}{ Transport } & \multicolumn{2}{|c|}{ Phase 1 } & Phase II \\
\cline { 2 - 5 } & No. & $\%$ & No. & $\%$ \\
\hline Hospital Ambulance & 35 & $5.05 \%$ & 111 & 22.5 \\
\hline Private Vehicle & 657 & $94.95 \%$ & 446 & 77.5 \\
\hline Total & $\mathbf{6 9 2}$ & $\mathbf{1 0 0}$ & $\mathbf{5 5 7}$ & $\mathbf{1 0 0}$ \\
\hline
\end{tabular}

Private vehicle was the type of transport maximum used by the patient. There has been a slight improvement in the number of patients utilizing hospital ambulance towards the end of study from $5.05 \%$ to $22.5 \%$. Maximum $85.5 \%$ of the patients from within Bhopal district reached SZH with in 2 hrs. 
Original Research Article

Table No.-5: Causes of referral.

\begin{tabular}{|c|l|c|c|c|c|}
\hline \multirow{2}{*}{$\begin{array}{c}\text { S. } \\
\text { No. }\end{array}$} & \multirow{2}{*}{ Cause of Referral } & \multicolumn{2}{|c|}{ Phase I } & \multicolumn{2}{c|}{ Phase II } \\
\cline { 3 - 6 } & & No. & $\%$ & No. & \multicolumn{1}{c|}{$\%$} \\
\hline 1 & Full term pregnancy with labour pains' & 153 & 22.11 & 58 & 10.42 \\
\hline 2 & Hypertensive disorders & 105 & 15.17 & 94 & 16.9 \\
\hline 3 & Anaemia & 89 & 12.9 & 92 & 16.52 \\
\hline 4 & Premature rupture of membranes & 42 & 6.06 & 42 & 7.54 \\
\hline 5 & Malpresentations & 34 & 4.91 & 28 & 5.02 \\
\hline 6 & Fetal distress & 21 & 3.03 & 32 & 5.7 \\
\hline 7 & Hemorrhage & 27 & 3.9 & 36 & 6.5 \\
\hline 8 & Abortions & 33 & 4.76 & 20 & 3.6 \\
\hline 10 & Others & 185 & 26.7 & 155 & 27.8 \\
\hline Total & & $\mathbf{6 9 2}$ & $\mathbf{1 0 0}$ & $\mathbf{5 5 7}$ & $\mathbf{1 0 0}$ \\
\hline
\end{tabular}

Maximum $16.9 \%$ of patients were referred in intrapartum period with no high risk factor associated, which proves to be unnecessary overburdening of the SZH. Among the high risk pregnencies, hypertensive disorders accounted for maximum i.e. $15.3 \%$ of the referrals followed by anaemia (14.5\%) and Premature rupture of membrane $(6.7 \%)$.

Table No.-6: Maternal outcome.

\begin{tabular}{|l|c|c|c|c|}
\hline \multirow{2}{*}{ Maternal Outcome } & \multicolumn{2}{|c|}{ Phase 1 } & \multicolumn{2}{c|}{ Phase II } \\
\cline { 2 - 5 } & No. & $\%$ & No. & \% \\
\hline Vaginal Delivery & 454 & 65.6 & 346 & 62.1 \\
\hline LSCS & 160 & 23.12 & 146 & 26.21 \\
\hline Laparotomy for Ectopic pregnancy & 06 & 0.86 & 06 & 1.07 \\
\hline Laparotomy for Rupture Uterus & 04 & 0.58 & 02 & 0.36 \\
\hline - Hysterectomy & 01 & & 0 & \\
\hline - Repair of Uterus & 03 & & 02 & \\
\hline Evacuation and curettage & 20 & 2.89 & 28 & 5.04 \\
\hline Cervical and Vaginal Exploration & 07 & 1.01 & 06 & 1.08 \\
\hline Manual removal of placenta & 04 & 0.57 & 01 & 0.18 \\
\hline Patient on conservative management & 37 & 5.37 & 22 & 3.96 \\
\hline Total & $\mathbf{6 9 2}$ & $\mathbf{1 0 0}$ & $\mathbf{5 5 7}$ & $\mathbf{1 0 0}$ \\
\hline
\end{tabular}

Maximum (64.05\%) patients referred undervent vaginal delivery which includes both high low risk patients $.24 .5 \%$ patients have undergone LSCS $.4 .72 \%$ of the patients were managed conservatively

Table No.-7: Perinatal outcome.

\begin{tabular}{|l|c|c|c|c|c|c|c|c|}
\hline & \multicolumn{2}{|c|}{ Still birth } & \multicolumn{2}{c|}{ Early neodeaths } & \multicolumn{2}{c|}{ NICU Admission } & \multicolumn{2}{c|}{ A \& H } \\
\hline & Phase I & Phase II & Phase I & Phase II & Phase I & Phase II & Phase I & Phase II \\
\hline LSCS & 6 & 6 & 8 & 11 & 37 & 33 & 109 & 96 \\
& $(3.75 \%)$ & $(4.11 \%)$ & $(5.00 \%)$ & $(7.53 \%)$ & $(23.12 \%)$ & $(22.60 \%)$ & $(68.13 \%)$ & $(65.76 \%)$ \\
\hline Vaginal & 29 & 20 & 19 & 13 & 56 & 36 & 35 & 227 \\
delivery & $(6.39 \%)$ & $(5.78 \%)$ & $(4.19 \%)$ & $(3.75 \%)$ & $(12.33 \%)$ & $(10.4 \%)$ & $(77.09 \%)$ & $(80.07 \%)$ \\
\hline
\end{tabular}

Maximum $72.33 \%$ babies are delivered vaginally and $27.67 \%$ babies are born by LSCS. Among Vaginal deliveries $78.37 \%$ babies are Alive \& Healthy, $11.5 \%$ needed NICU admission, 4\% were early neodeath and $6.13 \%$ babies were still born. Among LSCS deliveries 66.99\% babies are Alive \& Healthy, 22.67\% needed NICU admission, $6.21 \%$ were early neodeath and $3.93 \%$ babies were still born. 


\section{Original Research Article}

Table No.- 8: Maternal deaths.

\begin{tabular}{|l|c|c|}
\hline & No. & $\%$ \\
\hline Total Maternal deaths in SZH & 72 & \\
\hline Maternal deaths in Referred Patients & 60 & $83.33 \%$ \\
\hline Maternal deaths in referred patients from outside Bhopal & 40 & $66.67 \%$ \\
\hline Maternal deaths in referred patients from inside Bhopal & 20 & $33.33 \%$ \\
\hline
\end{tabular}

Out of total no. of maternal deaths during the study period, $83.33 \% \%$ of maternal deaths were in referred patients. Out of total maternal deaths in referred patients $33.33 \%$ of maternal deaths are in patients referred from inside Bhopal. Hypertensive disorders $(50 \%)$ have been the leading cause of maternal death followed by hemorrhage (30\%), Anaemia $(10 \%)$ \& Hepatitis $(10 \%)$.

\section{Discussion}

Pregnancy is not a disease \& pregnancy related, morbidity and mortality are preventable. Complications related to pregnancy $\&$ childbirth are among the leading causes of morbidity \& mortality of women of reproductive age in many parts of the developing world. About fifteen percent of all pregnancies will have some complication. Most complications occur randomly in both high and low risk patients. Life threatening complications can occur any time before, during and after delivery and quite often they are neither predictable nor preventable. However, if they are identified and addressed timely and if the basic and comprehensive emergency obstetric services are provided to all pregnant women closer to their homes; most of the maternal and perinatal deaths can be averted.

Early identification, initiation of early treatment and timely referrals are the crucial components for success of any maternal health intervention. Therefore, it is imperative to impart the knowledge and skills for early identification of complications and initiation of early treatment to all the health functionaries of the state.

Majority of patients are referred from Jawaharlal Nehru Hospital followed by Berasia \& private hospitals in Bhopal, and maximum number of patients are referred in intrapartum period with no high risk factors, which causes overutilization of higher level facilities like Sultaniazanana hospital. This is important because it has cost implication in resource constrained situation and because it may be detrimental to quality of care as the higher level facility becomes overburdened.

Hypertensive disorder (15.3\%) followed by Anaemia (14.5\%) \& PROM (6.75\%), have been the leading causes of referral which can be managed, right at the place of referral. Proper antenatal care is required to pick up high risk case especially early identification \& treatment of hypertensive disorder of pregnancy \& anaemia, which can improve the maternal \& fetal outcome. Maximum patients $(64.05 \%)$ underwent vaginal delivery including both low risk \& high risk patients. $24.5 \%$ patients underwent LSCS. Low risk patient's vaginal deliveries \& LSCS can be done at the referring center, their unnecessary referral overburdens the higher level facility. Perinatal outcome is better in patients with vaginal deliveries than those undergoing LSCS. This is because most of the caesarean sections were done for fetal distress, malpresentation specially transverse lie with hand prolapse \& obstructed labour. If there caesarean section are done at referring centers unnecessary delay in operative intervention can be avoided and perinatal morbidity \& mortality can be improved.

In our study $88.4 \%$ patients used private vehicle \& $11.6 \%$ patients could get hospital ambulance to reach Sultaniazanana hospital comparable to study done by Tadassekittila et al in which $72 \%$ patients used private taxi. Referral arrival time is also comparable which is 1 hours in $89.5 \%$ patients in their study \& 2 hours in our study. In their study the reasons of referral were mainly non medical like lack of skilled manpower, shortage of supplies including shortage of beds for admission, in contrast to our study in which inspite of skilled manpower availability of supplies patients are referred. Maximum patients referred are with no high risk factors, hypertensive disorder, Anaemia which can be managed at the referring site[5].

In another study done by Onwudiegwu $\mathrm{U}$ et al. it was seen that in Nigeria obstetric haemorrhage (24.6\%) was the most common cause of referral followed by labour disorder (19\%) \& hypertensive disorder (19\%). Not all pregnant women who decide to seek care at a medical facility in Nigeria arrive in time to be treated. Some die while trying to get there. Data on such deaths are, 


\section{Original Research Article}

however, scarce. In this study, conducted over a 5-year period (1995-99), when any pregnant woman was brought in dead into the Obafemi Awolowo University Teaching Hospitals Complex, Ile-Ife, Nigeria, the relatives were interviewed immediately to discover the immediate and remote causes. Reasons given for late presentation include: inability to obtain transportation in time $(41 \cdot 7 \%)$, inability of the health-care staff to detect an obstetric emergency early enough and refer to an appropriate centre $(33 \cdot 3 \%)$, inability of the referring hospital to perform an emergency caesarean section $(33 \cdot 3 \%)$, fear of caesarean section $(25 \%)$, unwillingness of drivers to travel by night (25\%) and no money to pay for hospital costs $(16 \cdot 7 \%)$.

Causes of death include eclampsia, ruptured uterus, severe postpartum haemorrhage, severe antepartum haemorrhage, sickle cell anaemia with crises and road traffic accidents. Prevention of 'brought-in' maternal deaths requires social transformation, overhauling the health-care delivery services and improving the socioeconomic status of the population[6].

In another study done at Govt, medical college Nanded in which $8.2 \%$ patients were referred patients of total obstetric admission in contrast to which in our study. Sultaniazanana hospital received $28.45 \%$ referred patients of total obstetric admission. In their study commonest conveyance used was private Jeep \& only $11 \%$ traveled by hospital ambulance, $91.20 \%$ patients reached district hospital within 1 hours\& Hypertensive disorder $(20 \%)$ is the main cause of maternal death followed by Haemorrhage (16\%) which is comparable to our study in Sultaniazanana hospital in which $88.4 \%$ patients travelled by private vehicle, $85 \%$ pafrenfs reached Suftama Zanana Hospital with in 2 hours. Hypertensive disorder (50\%) remain, the major cause of maternal death of followed by Haemorrhage (30\%)[7].

de Bernis L et al emphasized on skilled attendants for pregnancy, childbirth and postnatal care. Their paper sets out the rationale for ensuring that all pregnant women have access to skilled health care practitioners during pregnancy and childbirth. It described why increasing access to a skilled attendant, especially at birth, is not only based on legitimate demand and clinical common sense, but is also cost-effective and feasible in resource-poor countries. Skilled attendants need to be supported by a health system providing a legal and policy infrastructure, an effective referral system and the supplies that are necessary for effective care. A skilled attendant providing skilled care will help achieve the goals of reducing both maternal and child mortality. Health care professionals as individual practitioners, leaders and informers have an important role in making this a reality [8]. Rabia s et al studied pattern and obstetric risk factors of severe acute maternal morbidity (SAMM) and maternal death in tertiary care hospitalso that guideline can be formed for health personnel in an attempt to reduce the incidence of SAMM; maternal death. A prospective descriptive study was conducted in gynecology \& amp; obstetric department civil hospital Karachi. All the women admitted in gynaecology \& amp; obstetric department with case history fitting the definition of severe acute maternal morbidity and all maternal death were included in the study.

Both groups were comparatively analyzed for demographic characteristic and obstetric risk factors in each case Cases of SAMM in addition to audit of maternal death give more information regarding quality of maternity care system. As compared to our study in Sultaniazanana hospital in which patient in intrapartum period with no high risk factors accounted to maximum i.e. $16.26 \%$ followed by hypertensive disorder (16.03\%) $\&$ anaemia $(14.71 \%)[9,10]$.

The number of patients utilizing hospital ambulance from referral facility has been increased from 5.05\% to $22.5 \%$ towards the end of study. Maximum (83.7\%) patients are referred during 2:00 pm, to 8:00 am that is emergency hours, which indicates inadequate health facility during emergency hours. Maximum patient reach Sultaniazanana hospital with in two hour which is adequate time to manage complications unless, the patient is not referred late from the referring site. Turgut A, Ozler A et al studied to determine the predisposing factors, modes of clinical presentation, management modalities and fetomaternal outcomes of uterine rupture cases at a tertiary care center in Turkey. It was a retrospective analysis of 61 gravid ( $>20$ weeks of gestation) uterine rupture cases. Rupture of gravid uterus brings about potentially hazardous risks. Regular antenatal care, hospital deliveries and vigilance during labor with quick referral to a well-equipped center may reduce the incidence of this condition[11].

Akbar A, Laksana MA et al did work on maternal death risk factor score based on hospital reference pattern and maternal condition of eclamptic woman in Soetomo Hospital, Surabaya, Indonesia. Maternal Mortality Rate in Indonesia is still high, around 230/100,000 live birth in 2005. Eclampsia is the second most cause of maternal death (about 13\%). They had a very high prevalence of eclampsia in their center (Surabaya) about 


\section{Original Research Article}

$1.08 \%$ of all delivery. One of theirmain problem about eclampsia case was multiple referral hospital system, because they did'nt have many tertiary centers. It was thus assumed that high incidence of maternal death because of eclampsia is caused by this factor. A case control study was done with retrospective observational analytic design, involve all eclamptic woman whom referred and admitted to Soetomo hospital. There are 6 significant variable includes Maternal complication ( $\mathrm{ICH}$, renal failure, lung oedema), Maternal ages $>35$ years, antihypertensive drugs, multiple hospital referral, multiparity, and eclampsia type that can be made a scoring system. They developed scoring system based on risk factor that can be used to predict maternal death event on eclamptic woman[12].

Sunita SP, Nacharaju M et al studied maternal and fetal outcome in booked and unbooked patients undergoing emergency LSCS. Caesarean section is the most commonly done Obstetric surgery and the outcome of surgery differs depending on various factors. Maternal and Fetal morbidity effects the quality of life, effect on maternal and foetal morbidity depends on proper follow up during antenatal period. Their study was under taken to find out the difference in maternal and fetal outcome between booked cases with proper antenatal follow up and un-booked cases. It was a comparative study conducted at Rural Medical College in Telangana over a period of one year. Various parameters of Maternal Morbidity, Neonatal Morbidity, and Mortality were compared in both the groups [13].

Indra N.did study of maternal and perinatal outcome in obstructed labour Obstructed labour (OL) is a major cause of both maternal and newborn morbidity and mortality. Obstructed labour ranked 41st in GBD 1990, representing $0.5 \%$ of the burden of all conditions and $22 \%$ of all maternal conditions. It was estimated to be the most disabling of all maternal conditions.

Obstructed labour accounts for $8 \%$ of maternal mortality in developing countries. Hence this study was conducted to study the causes, clinical feature and maternal and perinatal outcome in obstructed labour. It was concluded that majority of the patients were, emergency admissions and were from rural areas with high prevalence of and hence maternal morbidity and perinatal mortality was high. This can be improved with good antenatal care, patient education, early diagnosis and timely referral to higher centres. At tertiary centre with aggressive management and good neonatal care improves perinatal and maternal outcome[14].

Ethical approval: Taken

\section{Conclusion}

Hence it can be concluded that a lot of low risk patients are being referred to Sultaniazanana hospital from inside Bhopal, most of whom delivers vaginally, this only adds to burden of Sultaniazanana hospital \& causes overutilization of services.

Maximum patients were referred during emergency hours (2pm - 8am) which reflects negligence \& irresponsibility at part of health personnel.

Most common cause of referral as well as maternal mortality is hypertensive disorder which can be prevented \& diagnosed early by proper antenatal care. Also, administration of $1^{\text {st }}$ dose of magnesium sulfate therapy must be done in all cases of eclampsia \& severe preeclampsia prior to referral.

Also workshop \& continued medical education should be held regularly to update clinical knowledge \& skills of health personnel's. Emergency obstetric care training todoctors should beprovided.

What this study add to existing knowledge: All the patients referred have incomplete information on referral letter so universal referral form is devised to be provided to various health facilities. Hypertensive disorder of pregnancy has been the common causes of maternal mortality, followed by haemorrhage \& anaemia all of which are preventable by proper antenatal care $\&$ early diagnosis of risk factors.

Funding: Nil, Conflict of interest: Nil Permission from IRB: Yes

\section{References}

1. World Health Organization. Making pregnancy safer: the critical role of the skilled attendant: a joint statement by WHO, ICM and FIGO.

2. World Health Organization. Strengthening midwifery within safe motherhood: report of a collaborative ICM/ WHO / UNICEF pre- Congress workshop, Oslo, Norway, 23-26 May 1996. Geneva: World Health Organization; 1997.

3. O'Herlihy C. Reviewing maternal deaths to make motherhood safer: 2006-2008. BJOG: An International Journal of Obstetrics \&Gynaecology. 2011 Oct;118(11): 1403-4.

4. World Health Organization. The World health report: 2005: make every mother and child count. 


\section{Original Research Article}

5. Tadesse Kitilla et al. Reason for referrals and time spent from referring sites to arrival at Tikur Anbessa Hospital in emergency obstetrics prospective study. Ethiop. J. Health Dev ,2001;15(1):17-23

6. Orji EO, Ogunlola IO, Onwudiegwu U. Brought-in maternal deaths in south-west Nigeria. J Obstet Gynaecol. 2002 Jul; 22(4):385-8.DOI:10.1080/0144361 0220141326

7. Wagle S, Shah N. Government Funded Health Insurance Scheme in Maharashtra: Study of Rajiv Gandhi Jeevan dayee Aarogya Yojana. CEHAT, Mumbai, http://www. cehat. org/uploads/files/RGJAY\% 20 Report. pdf. 2017.

8. de Bernis L, Sherratt DR, AbouZahr C, Van Lerberghe W. Skilled attendants for pregnancy, childbirth and postnatal care. British medical bulletin. 2003 Dec 1;67(1):39-57.

9. Rabia S, Tabbasum R, Perveen F, Ali A. Pattern and obstetric risk factors of severe acute maternal morbidity (SAMM) and maternal death in tertiary care hospital. Karachi Medical Channel. 2011 Jan 1;17(1).
10. Haider G, Zehra N, Munir AA, Haider A. Frequency and indications of cesarean section in a tertiary care hospital. Pak J Med Sci. 2009 Oct 1;25(5):791-6.

11. Turgut A, Ozler A, Siddik Evsen M, et al. Uterine rupture revisited: Predisposing factors, clinical features, management and outcomes from a tertiary care center in Turkey. Pak J Med Sci. 2013 May;29(3):753-7.

12. Akbar A, Laksana MA, Dachlan EG, Prasetyo B. OS017. Maternal death risk factor score based on hospital reference pattern and maternal condition of eclamptic woman in Soetomo Hospital, Surabaya, Indonesia. Pregnancy Hypertension: An International Journal of Women's Cardiovascular Health. 2012 Jul 1; $2(3): 183$.

13. Sunita SP, Nacharaju M, Kaul R, Suchetha D. Maternal and fetal outcome in booked and unbooked patients undergoing emergency LSCS. Journal of Evolution of Medical and Dental Sciences. 2015 May 25; 4 (42):7402-9.

14. Indra N. Study of maternal and perinatal outcome in obstructed labour (Doctoral dissertation).

\section{How to cite this article?}

Nagar N, Gupta P. Maternal and foetal outcome in patients referred to tertiary hospital. Obs Rev: J obstet Gynecol 2019;5(1):37-44.doi:10.17511/joog.2019.101.08. 